\title{
Comunicação, inovação e avaliação no setor público: o uso de marketing social em dois diferentes casos no Rio Grande do Sul
} Communication, innovation and evaluation in the public sector: the use of social marketing in two different cases in Rio Grande do Sul.

\section{Paulo Ricardo dos Santos Meira}

Analista legislativo; produtor de marketing do Senado Federal; bacharel em Comunicação Social, pela Faculdade de Biblioteconomia e Comunicação da Universidade Federal do Rio Grande do Sul - Fabico/UFRGS; mestre em Administração (Marketing), pelo Programa de Pós-Graduação em Administração da Universidade Federal do Rio Grande do Sul - PPGA/UFRGS; doutor em Administração (Marketing), pela mesma instituição.

E-mail: paulorsm@senado.gov.br

\section{Cristiane Pizzutti dos Santos}

Professora do Programa de Pós-Graduação em Administração da Universidade Federal do Rio Grande do Sul - PPGA/UFRGS; bacharel em Comunicação Social, pela Universidade Federal de Santa Maria - UFSM; mestre em Administração (Marketing), pelo PPGA/ UFRGS; e doutora em Administração (Marketing), pela mesma instituição.

E-mail: cpsantos@ea.ufrgs.br

\begin{abstract}
Resumo
Uma das áreas de marketing cada vez mais utilizadas na gestão de serviços públicos é o marketing social. O presente artigo apresenta dois estudos de caso em que houve utilização das ferramentas dessa área específica do marketing. Os casos foram o Programa "Novo Sinal", da Prefeitura Municipal de Porto Alegre, e os programas de imunização do Centro Estadual de Vigilância em Saúde, do Governo do Rio Grande do Sul. São relatados neste trabalho os objetivos, as estratégias e as dificuldades encontradas em cada caso, que servem como benchmarking para outras iniciativas semelhantes na área.
\end{abstract}

Palavras-chave: estudos de caso, marketing social, mudança social planejada.

\begin{abstract}
One of the marketing areas increasingly used by public policy makers and public agencies is social marketing. This paper presents two case studies in which social marketing tools kit has been useful. The cases were the "pedestrian crossing new signal case" of Porto Alegre City Hall, and the Immunological Programme of the Public Health State Center (CESV/RS) of the Government of Rio Grande do Sul. The cases serve as benchmarking for other similar initiatives.
\end{abstract}

Keywords: case studies, social marketing, planned social change. 
Comunicação, inovação e avaliação no setor público: o uso de marketing social em dois diferentes casos no Rio Grande do Sul

\section{Introdução}

Marketing social é uma área que vem sendo aprofundada paulatinamente desde o início dos anos 1970, embora ainda carente de investigações sobre as formas de avaliação do desempenho dos programas realizados. Neste artigo, são apresentados dois estudos de caso, do sul do Brasil, nos quais houve plena utilização das ferramentas de marketing social, tal como definido pelo Social Marketing Institute - SMI: "é o planejamento e implementação de programas desenhados para criar mudança social a partir de conceitos advindos do marketing comercial'".

\section{Marketing social}

Apesar de Pringle \& Thompson (2000) utilizarem as expressões marketing social e marketing relacionado a causas como sinônimas, cabe distingui-las. O marketing de causas sociais - MCS ou marketing relacionado a causas - MRC é uma parceria entre empresas e organizações da sociedade civil, que utiliza o poder de suas marcas em benefício mútuo e que, eventualmente, sofre críticas por explorar causas simpáticas ao público com objetivos de melhorar o desempenho comercial (DRUMWRIGHT, 1996: 83)². O MRC pode ser útil à imagem - e ao desempenho comercial - da empresa, desde que os valores da causa em questão estejam alinhados aos valores dos consumidores (MACHADO \& Damacena, 2006). O benefício, no MRC, vai além da empresa em si: se dá tanto para a empresa quanto para a causa de caridade, e ainda para o cliente, mas "a ênfase é em marketing" (SMITH \& HigGins, 2000: 307). Conforme reforçou Fontes (2008: 76), "[...] no caso de uma empresa condicionar sua atuação social com o objetivo de agregar valor social ao seu produto, ela não [grifo dos autores] estará fazendo marketing social". Para ele, a diferença está no foco do "P" de produto da estratégia: se o foco principal é o produto comercializado pela empresa, e a causa social está em um segundo plano, trata-se, nesse caso, de marketing comercial ligado a uma causa.

Marketing social, por seu turno, costuma ser praticado por governos, agências de financiamento e organizações da sociedade civil bem mais do que por empresas (FonTES, 2008). Seu objetivo é conscientizar ou sensibilizar as pessoas a respeito de um tema de natureza social, ou buscar

\footnotetext{
${ }^{1}$ Disponível em: <http://www.social-marketing.org/sm.html>. Acesso em: 17 de agosto de 2009.

${ }^{2}$ Cone, Phares \& Gifford (2001) ainda exploraram o conceito de cause branding, quando uma empresa liga sua imagem de marca a uma campanha social, de modo a obter proveitos tanto comerciais, pela reputação ampliada de marca, quanto para a causa social em si.
}

uma mudança de comportamento social. Por sua vez, marketing societal pode ser entendido como um processo no qual as funções e responsabilidades de um determinado segmento de marketing são vistas como inter-relacionadas com os outros segmentos da estrutura social. Assim, marketing relaciona-se com os ambientes legal, político, educacional e com a comunidade em geral, ou seja, há uma responsabilidade para com indivíduos outros que não somente os consumidores (BARTELS, 1974: 74). Como trouxeram Kerin, Hartley, Berkowitz \& Rudelius (2008: 21), o conceito de marketing societal é a "visão de que as organizações devem satisfazer as necessidades dos consumidores de forma que proporcionem o bem-estar para a sociedade" - produzindo, por exemplo, com menor utilização de recursos naturais, promovendo reciclagem, reinvestindo socialmente -, o que difere, por conseguinte, do conceito de marketing social no presente entendimento da literatura.

No Quadro 1, a seguir, os conceitos estão definidos conforme o entendimento adotado para o presente trabalho, agregando, ainda, três conceitos correlatos na literatura, que eventualmente geram confusão entre os que deles fazem uso.

Entre as definições atuais de marketing social, tem-se: "[...] o uso dos princípios e técnicas de marketing para influenciar um público-alvo a voluntariamente aceitar, rejeitar, modificar ou abandonar um comportamento para o benefício de indivíduos, grupos ou da sociedade como um todo" (KOTLER \& LEE, 2008: 207), ou a anterior definição de Lefebvre \& Flora (1988: 300), a saber: "programas em larga escala com foco na mudança comportamental" e "o planejamento e implementação de programas delineados para a consecução de mudança social usando conceitos advindos do marketing comercial" (ANDREASEN, 2008: 1).

Há importantes diferenças entre o marketing social e o comercial (RothschILD, 1998; KotLeR, RoBeRto \& LeE, 2002), e as mais relevantes estão no Quadro 2, a seguir.

A perspectiva de marketing social para a mudança social planejada tem sido utilizada com êxito em diferentes programas (Gordon; McDermott; Stead \& Angus, 2006), desde causas sociais mais comuns a atividades de popularização da ciência ao grande público (DOMEGAN, 2007) e programas de conservação dos oceanos (BATES, 2010). Peattie \& Peattie (2009: 260) verificaram a eficácia da perspectiva de marketing social na promoção de práticas de consumo responsável e de-marketing de produtos com risco à saúde da população, enquanto Chance \& Deshpandé (2009) demonstraram bons resultados dessa perspectiva [marketing social] no tratamento de população pobre infectada com HIV; Hampson, Martin, Jorgensen \& Barker (2009) fizeram uso dessa abordagem para a questão de nutrição de famílias de baixa renda; por sua vez, Gordon \& 


\section{Comunicação, inovação e avaliação no setor público: o uso de marketing social em dois diferentes casos no Rio Grande do Sul}

Quadro 1: Descrição dos diferentes conceitos

\begin{tabular}{|c|c|c|}
\hline Conceito & Definição & Fonte \\
\hline $\begin{array}{l}\text { Marketing } \\
\text { societal }\end{array}$ & $\begin{array}{c}\text { É a visão de que as organizações devem satisfazer as } \\
\text { necessidades dos consumidores de forma que proporcionem o bem-estar } \\
\text { para a sociedade (por exemplo, desenvolvimento de automóveis movidos } \\
\text { a eletricidade, em vez de derivados de petróleo). }\end{array}$ & $\begin{array}{l}\text { Kerin, Hartley, } \\
\text { Berkowitz \& } \\
\text { Rudelius } \\
\text { (2008: } 21)\end{array}$ \\
\hline $\begin{array}{c}\text { Marketing ligado a } \\
\text { causas sociais }\end{array}$ & $\begin{array}{l}\text { Uma ferramenta estratégica de marketing e de posicionamento } \\
\text { que associa uma empresa ou marca a uma questão ou causa social } \\
\text { relevante, em benefício mútuo (por exemplo, uma empresa de comunicação que } \\
\text { promova uma campanha institucional contra o consumo de crack). }\end{array}$ & $\begin{array}{c}\text { Pringle \& } \\
\text { Thompson (2000: 3). }\end{array}$ \\
\hline $\begin{array}{l}\text { Marketing } \\
\text { social }\end{array}$ & $\begin{array}{l}\text { O uso dos princípios e técnicas de marketing para influenciar um } \\
\text { público-alvo a voluntariamente aceitar, rejeitar, modificar ou abandonar um } \\
\text { comportamento para o benefício de indivíduos, grupos ou da sociedade como um } \\
\text { todo (por exemplo, um programa público de vacinação contra a gripe H1N1). }\end{array}$ & $\begin{array}{l}\text { Kotler \& Lee, } \\
\text { 2008:. } 207 .\end{array}$ \\
\hline $\begin{array}{l}\text { Responsabilidade } \\
\text { social organizacional } \\
\text { [ou empresarial] }\end{array}$ & $\begin{array}{l}\text { A responsabilidade social empresarial é o comprometimento } \\
\text { permanente das empresas com a qualidade de vida ao realizar os } \\
\text { seus relacionamentos e negócios com postulados éticos. }\end{array}$ & $\begin{array}{l}\text { Giacomini Filho, } \\
\text { Costa, Silva \& Govatto, } \\
\text { Kahler (2004: } 15)\end{array}$ \\
\hline $\begin{array}{l}\text { Terceiro } \\
\text { Setor }\end{array}$ & $\begin{array}{l}\text { [Coexistindo com o setor público (Estado) e o privado (de iniciativa particular)], } \\
\text { engloba um conjunto de organizações sociais sem fins lucrativos (associações, } \\
\text { fundações e institutos, dentre outros), presentes desde longa data na sociedade, } \\
\text { com uma atuação voltada ao atendimento de necessidades de segmentos da } \\
\text { população e unidas por uma mesma legislação reguladora. }\end{array}$ & Coelho (2000: 17) \\
\hline $\begin{array}{l}\text { Organizações } \\
\text { sem fins } \\
\text { lucrativos }\end{array}$ & $\begin{array}{l}\text { Agentes não econômicos e não estatais que procuram atuar, } \\
\text { coletiva e formalmente, para o bem-estar de uma comunidade } \\
\text { ou sociedade local, sub-regional ou regional, nacional ou internacional. }\end{array}$ & Tenório (1999: 89) \\
\hline
\end{tabular}

Fonte: organizado pelos autores.

Quadro 2: Diferenças simplificadas entre o marketing comercial e social

\begin{tabular}{|c|c|c|}
\hline & Marketing comercial & Marketing social \\
\hline Tipo de produto vendido & Produtos comerciais (mercadorias e serviços) & Mudança comportamental \\
\hline Objetivo primário & Ganho financeiro & Ganho individual ou societal \\
\hline Concorrência & $\begin{array}{c}\text { Outras empresas que ofereçam mercadorias e } \\
\text { serviços similares }\end{array}$ & $\begin{array}{c}\text { O comportamento atual, ou } \\
\text { preferido, pelo público-alvo }\end{array}$ \\
\hline
\end{tabular}

Fonte: adaptado de Kotler, Roberto \& Lee (2002:10).

Moodie (2009) verificaram o sucesso da perspectiva de marketing social para tratamento do problema de vício em jogos de azar no Reino Unido; enquanto Watson, Tomar, Dodd, Logan \& Choi (2009) verificaram sucesso dessa abordagem para disseminação de prevenção de câncer de boca e outras enfermidades afins, como também estudos no Brasil reportam o uso de marketing social nas políticas públicas de saúde (SILVA, 2005).

\section{Método}

Utilizou-se, inicialmente, pesquisa bibliográfica da literatura acadêmica e gerencial a respeito de maketing social. Essa técnica, denominada de revisão bibliográfica por
Boyd, Westfall \& Stasch, (1989), consiste na revisão de literatura conceitual, literatura gerencial e, frequentemente, estatísticas publicadas. Por sua vez, o método de estudo de caso, para Yin (2001: 32), é uma investigação empírica que analisa um fenômeno contemporâneo em seu contexto na vida real, sobretudo quando os limites entre o fenômeno e o contexto não estão claramente definidos. O estudo baseia-se "em várias fontes de evidências, com os dados precisando convergir em um formato de triângulo" (p. 33).

A estratégia de pesquisa por estudo de caso foi por vezes confundida como uma mera etapa exploratória de outro tipo de pesquisa (YIN, 2001: 31), mas tem sido crescentemente valorizada no meio acadêmico. É o delineamento de pesquisa preferido, segundo Yin (2001: 19), quando se 


\section{Comunicação, inovação e avaliação no setor público: o uso de marketing} social em dois diferentes casos no Rio Grande do Sul

colocam questões do tipo "como" e "por quê", quando o pesquisador "tem pouco controle sobre os eventos e quando o foco se encontra em fenômenos contemporâneos inseridos em algum contexto da vida real". Executou-se o estudo de dois casos de programas de marketing social, e os informantes-chave dos estudos de caso foram de três instâncias: (1) planejadores / coordenadores dos programas de marketing social; (2) criadores da campanha em termos de comunicação publicitária; e (3) executores dos programas.

A coleta de dados consistiu de observação direta, entrevistas em profundidade com roteiro semiestruturado com os informantes-chave de cada caso e levantamento documental com base em material de imprensa, websites de informação ou corporativos, material de campanha e relatórios de trabalho, conforme preconizou Yin na utilização de "várias fontes de evidências" (2001: 104) para uma maior qualidade na investigação.

As unidades de análise deste estudo, que atendem aos critérios de escolha anteriormente citados, são os casos apresentados nos itens seguintes.

a) Empresa Pública de Transporte e Circulação - EPTC. Há um quadro grave de vítimas fatais (50 mil vítimas fatais por ano no Brasil; 1,6 mil, no Rio Grande do Sul) e não fatais no trânsito brasileiro (estimadas em 450 mil por ano, pelo Departamento Nacional de Trânsito Denatran) e que, em Porto Alegre, a EPTC, ligada à Prefeitura Municipal de Porto Alegre, buscou enfrentar pelo Programa "Novo Sinal".

b) Centro Estadual de Vigilância em Saúde/RS. Órgão da Secretaria Estadual da Saúde, do Governo do Estado do Rio Grande do Sul, cujos programas abordados foram o enfrentamento às hepatites virais - estima-se que cerca de 200 mil gaúchos estejam, alguns sem sequer sabê-lo, infectados com um dos três tipos mais comuns da doença no Estado, a saber, hepatite A, B ou $\mathrm{C}-\mathrm{e}$ a vacinação para a gripe $\mathrm{A}$ - vírus $\mathrm{H} 1 \mathrm{~N} 1$, detalhados mais adiante neste trabalho.

A análise dos estudos de caso foi feita por análise documental (GIL, 1999; YıN, 2001) e análise de conteúdo das entrevistas (BARDIN, 1977; FLICK, 2004; VERGARA, 2008). Em estudos de caso, "o uso mais importante de documentos é corroborar e valorizar as evidências oriundas de outras fontes" (YIN, 2001: 109). Houve uma pré-análise do material, com leitura flutuante e escolha dos documentos, formulação dos objetivos, preparação do material, sua exploração e o tratamento dos resultados e interpretação, conforme preconizado por Bardin (1977: 95-102). Como forma de análise, realizou-se a chamada análise qualitativa do tipo global que, conforme esclareceu Flick (2004: 205), tem por objetivo "uma visão geral do espectro temático do texto" ou documentos analisados.

\section{Estudos de Caso}

Nesta seção, apresentam-se os casos da Empresa Pública de Transporte e Circulação e do Centro Estadual de Vigilância em Saúde/RS.

\subsection{Empresa Pública de Transporte e Circulação}

O Programa "Novo Sinal" surgiu, em 2009, em um contexto no qual havia, em Porto Alegre, capital do Rio Grande do Sul, uma população de aproximadamente 1,4 milhão de habitantes e uma frota de 660 mil veículos. O Projeto de Qualificação do Trânsito e Redução de Acidentes de Porto Alegre, do qual derivou mais recentemente o Programa "Novo Sinal", foi elaborado em 2005, ano em que houve 22 mil acidentes registrados em Porto Alegre, que resultaram em seis mil feridos, dos quais 1,3 mil foram atropelamentos. Ao todo, no ano, foram 156 mortes, sendo 84 delas ocasionadas por atropelamentos.

A responsabilidade do gerenciamento do trânsito é da Secretaria Municipal de Mobilidade Urbana, que mede o desempenho de suas campanhas de trânsito seguro pelo índice de acidentalidade de trânsito e pelo número de pessoas abrangidas por ações de educação para o trânsito.

O indicador "índice de acidentalidade de trânsito" mede o número de acidentes de trânsito em relação à frota registrada no município e utiliza a seguinte fórmula:

\section{$\mathrm{IA}=\Sigma$ acidentes $\times 10.000$}

Frota total de veículos

O programa se inicia com foco no respeito à faixa de travessia de pedestres, intitulado "Porto Alegre tem um Novo Sinal de trânsito". O objetivo, conforme apresentou o relatório de campanha, é "colocar as pessoas em pé de igualdade e corresponsáveis por uma mudança de atitude em relação à faixa de travessia de pedestre em prol de um trânsito mais harmonioso e que beneficie a todos". Esse novo sinal consiste em o pedestre estender a mão diante de uma faixa de travessia não semaforizada (pois, neste caso, é o semáforo que prevalece, sendo este um código de comunicação entre pedestres e condutores, que indica a vontade expressa do pedestre de atravessar a via, pela faixa).

O investimento da Prefeitura Municipal de Porto Alegre foi de 2 milhões de reais, usados para contratação de empresa de pesquisa, produção de filmes e vinhetas, construção do hotsite <http://www.novosinal.com.br> e produção das demais peças publicitárias, além da 


\section{Comunicação, inovação e avaliação no setor público: o uso de marketing social em dois diferentes casos no Rio Grande do Sul}

contratação de promotores para as ações corpo a corpo nas vias públicas, e também de um valor adicional, pela Secretaria Municipal de Mobilidade Urbana, investido em revitalização, nova pintura e implantação de novas sinalizações de trânsito na cidade.

A primeira fase da campanha, de 2009-2010, consistiu, a partir de um plano de marketing, na definição de logomarca do programa, definição dos mecanismos de busca de adesão pela sociedade como um todo (imprensa, formadores de opinião, associações empresariais, igrejas, partidos políticos, três poderes, ONGs, entidades de classe, associações sociais, integração com outros órgãos de trânsito e instituições de ensino), definição das áreas e períodos de intervenções, e ações específicas nos campos de educação, de engenharia de tráfego e de fiscalização.

A segunda fase, que se iniciou em 2010 , é de intensificação e expansão do uso de equipamentos eletrônicos de fiscalização e ampliação do efetivo de agentes de fiscalização de trânsito.

Os objetivos do programa encontram-se explicitados a seguir.

\section{Objetivo geral}

Realizar uma campanha que humanize o trânsito, colocando as pessoas em pé de igualdade e corresponsáveis por uma mudança de atitude em relação à faixa de travessia de pedestres em prol de um trânsito mais harmonioso e que beneficie a todos.

\section{Objetivos específicos}

a) estabelecer um código de comunicação entre condutores e pedestres, que indique a vontade do transeunte de atravessar na faixa de travessia de pedestres;

b) sensibilizar todos os públicos com ações de educação e fiscalização de trânsito para o respeito à faixa de travessia de pedestres;

c) incentivar os diferentes segmentos da sociedade a serem protagonistas de ações que contribuam para o respeito à faixa de travessia de pedestres.

O esforço de campanha envolveu ainda anúncios na imprensa (anteriores ao levantamento em si), promotores com adesivagem de veículos, reforço em placas de sinalização, outdoor (ilustrado na Figura 1), cancelas de shopping centers e centros comerciais, busdoor, mídia em táxis, comercial de TV com testemunho de diversas personalidades, jingles, peças na web, adesivos em calçadas e criações artísticas produzidas por populares na Internet, ba- seadas no novo sinal, no canal virtual YouTube.

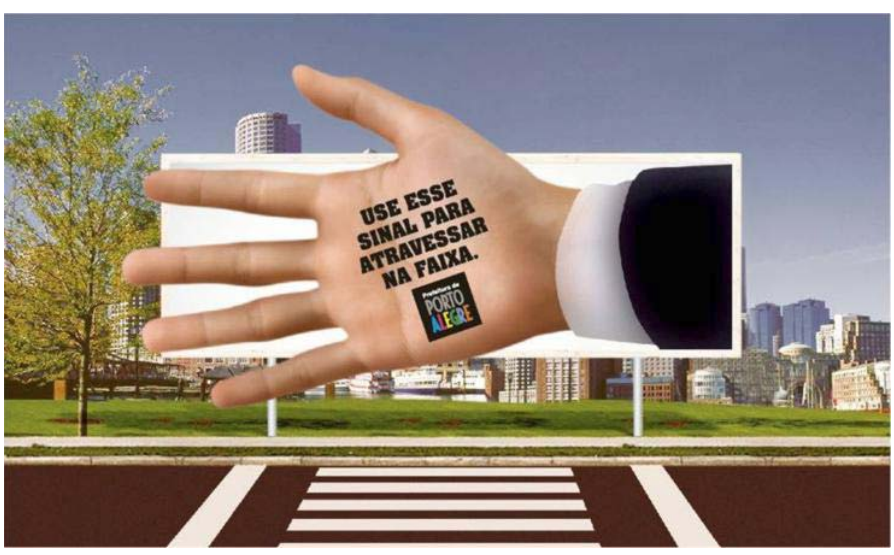

Figura 1: Outdoor com aplique da Campanha "Novo Sinal" Fonte: cortesia Paim Comunicação.

Além disso, é feito o controle das demandas de trânsito a partir do site e do Disque-Faixa, e uma mensagem de lembrete da campanha em todas as respostas a usuários feitas pela EPTC. Da mesma forma, contatos realizados pelo site, antes da resposta formal, já recebem uma resposta automática (vide Figura 2), que lembra sobre a campanha e, conforme salientou o executivo Ricardo Gomes, aumenta a credibilidade do programa pelo fato da instantaneidade do retorno automático, o que diminui a percepção de tempo decorrido até a resposta personalizada ao e-mail.

Como resultados, o programa apresentou as seguintes realizações:

a) uma rede de empresas, ONGs e escolas se engajaram na campanha, disseminando o novo sinal pela cidade. Por exemplo, uma rede de estacionamentos colocou a

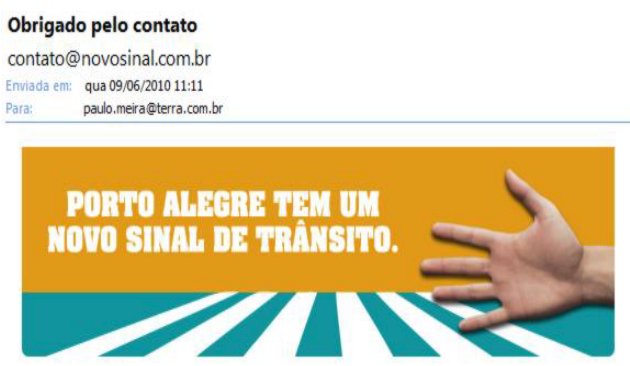

Obrigado pelo seu contato e interesse em saber mais sobre o novo sinal de trânsito de Porto Alegre. Em breve, entraremos em contato.

Ajude a divulgar o novo sinal. No site www novosinal com.br, você pode baixar conteúdos e passar a ideia adiante. Porto Alegre agradece.

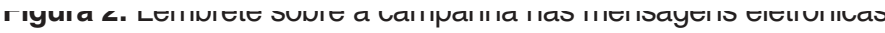
Fonte: arquivo pessoal. 


\section{Comunicação, inovação e avaliação no setor público: o uso de marketing social em dois diferentes casos no Rio Grande do Sul}

campanha gratuitamente em suas cancelas durante um mês, uma empresa de outdoors cedeu pontos gratuitamente para a campanha, e uma concessionária de automóveis produziu a mesma ideia básica da "mão", com sua marca própria em vez do brasão da Prefeitura;

b) formadores de opinião, como Neto Fagundes, Felipe Vieira, Tania Carvalho e Zé Victor Castiel, e os jogadores de futebol Guiñazu, do Internacional, e Victor, do Grêmio, que emprestaram sua imagem sem cachê nos comerciais, como apoio ao programa;

c) no balanço inicial de quatro meses, de setembro a dezembro de 2009, houve uma redução no índice de acidentalidade de 4,6\% em relação ao mesmo período no ano anterior (no primeiro mês, a redução chegou a $20 \%$ no número de acidentes);

d) geração de mídia espontânea sobre o programa (páginas gratuitas em jornais locais e regionais, como exemplificado na Figura 3);

e) disseminação do gesto do sinal para outras cidades do Estado (o gesto foi feito, durante o verão de 2009/2010, no litoral gaúcho e catarinense - o que, curiosamente, só fazia sentido para os porto-alegrenses que tivessem sido expostos à campanha - e o Município de Osasco, em São Paulo, passou dois dias em imersão na agência e na Prefeitura, para entender o programa e adaptar seu modelo;

f) adesão formal dos municípios de Esteio, Alvorada, Cachoeirinha, Guaíba, Santa Cruz e Montenegro. A estes, a Prefeitura e a agência cederam, sem custo, os layouts das peças, adaptados para uso com outra marca;

g) a campanha foi, na semana de seu lançamento, o quinto assunto mais postado, em nível nacional, na ferramenta Twitter, em função da ação viral com o vídeo "Náufrago", em que um pedestre engravatado chegava a criar barba de tanto esperar pelos motoristas para que pudesse atravessar o sinal;

h) a reflexão sobre um resultado adicional reportado culminou na integração, à estrutura conceitual, da variável "avaliação externa por experts ou pares", uma vez que o programa recebeu premiações do mercado publicitário, em eventos reconhecidos, o que não deixa de ser outra forma de avaliação da competência de sua execução ${ }^{3}$. A lista de premiações envolve os seguintes itens: Salão ARP da Propaganda 2009 - Anunciante do Ano - Prefeitura de Porto Alegre (campanha do Trânsito) /

3 Disponível em: <http://www.portaldapropaganda.com/ comunicacao/2010/04/0005/arquivo_ext/Vencedores VotoPopular2010.pdf>.
Grand Prix de Platina - Um gesto no trânsito: o sinal de um novo comportamento. Paim Comunicação - Prefeitura de Porto Alegre / Mídia Ambiente - Ouro - Título: Cancela - Cliente: Prefeitura de Porto Alegre - Agência: Paim Comunicação / Área de Marketing Promocional - Prata / Bronze: Título: Novo Sinal - Cliente: Prefeitura de Porto Alegre - Agência: Paim Comunicação / Internet Campanhas - Bronze - Cliente: Prefeitura de Porto Alegre - Título: Campanha Novo Sinal - Agência: Paim Comunicação;

ii) convite para apresentação do programa em evento nacional de segurança no trânsito, realizado na Bahia.

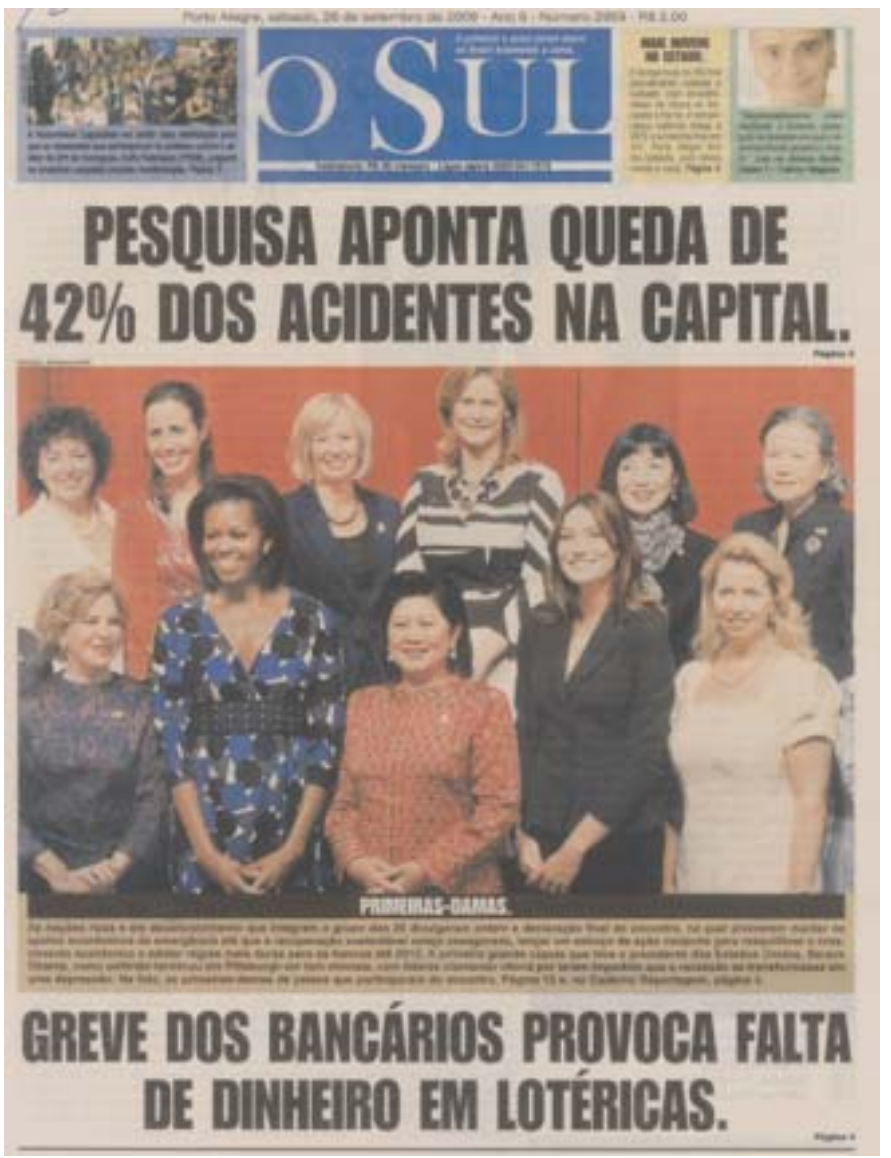

Figura 3: Capa de jornal aponta resultados do programa Fonte: Press clipping da agência Paim.

Como a Assessoria de Educação para o Trânsito - Asset é de atuação, sobretudo, operacional, não se envolveu no planejamento da campanha, mas o fará a partir de agora, na etapa que é chamada de Fase 2, lançada publicamente no Ginásio Tesourinha, com sketches de teatro e shows musicais. Enquanto a Fase 1 foi precipuamente campanha de informação e persuasão, a Fase 2 reforçará a puni- 


\section{Comunicação, inovação e avaliação no setor público: o uso de marketing social em dois diferentes casos no Rio Grande do Sul}

ção pelo não comportamento desejado, pelo incremento da fiscalização e da própria infraestrutura tecnológica e de sinalização.

Dessa forma, a avaliação de diagnóstico inicial se deu diretamente pelo Gabinete do Prefeito. Como brincou um dos integrantes, "receberam o filho pronto" da Coordenação de Comunicação do Gabinete do Prefeito. A Asset se envolverá, a partir de agora, na avaliação formativa à medida que o programa está tendo sua Fase 2 implementada. Para a avaliação de diagnóstico, a Prefeitura e a agência destinaram cinco meses em planejamento, antes de proceder à campanha em si. Para promover uma sensibilização das empresas de mídia, grupos de comunicação e instituições públicas e entidades de classe, a agência e a Prefeitura fizeram 42 diferentes apresentações privadas da campanha antes de seu lançamento.

A coordenadora de comunicação, Aline Kusiak, explicou como o planejamento foi feito pari passu com a agência de comunicação licitada: "A agência Paim acompanhou e orientou o trabalho desde sua concepção, e há muita transparência de informações entre o Gabinete, o Ricardo Gomes [executivo da Paim] e a EPTC".

O Instituto Methodus, sob encomenda, realizou a pesquisa entre abril e maio de 2009, que serviu como subsídios. A agência e o Gabinete do Prefeito, por intermédio da Coordenação de Comunicação, elencaram a faixa como "símbolo de respeito", conforme esclareceu Diego, que sumarizaria os demais aspectos do trânsito "tal como na experiência de Brasília".

Uma forma de monitoramento é feita pela Chefia de Gabinete da EPTC, que responde ao link próprio do programa no site (http://www.novosinal.com.br), e ao Disque-Faixa (0800); assim, na Assessoria do Gabinete, eles têm outra forma indireta (mais qualitativa), de retorno de avaliação do "Novo Sinal". Na opinião da agência, essa foi inclusive uma forma de se "transformar críticas em informação de subsídios", pois reclamações específicas de desgaste de pintura acarretavam a alteração do cronograma normal de repinturas das faixas de travessia, fazendo o cidadão perceber que havia resposta às demandas, agregando credibilidade à campanha [há 6.190 faixas de travessia na cidade, o que faz com que o cronograma normal de repintagem de cada uma seja, em geral, demorado].

O indicador de avaliação pela mídia pode ser ilustrado na Figura 4, de Gonzatto (2010), que realiza, diretamente, uma avaliação a respeito do Programa "Novo Sinal", classificando-o como de parcial sucesso: em comparação de dois períodos determinados, enquanto o número de atropelamentos aumentou em $8 \%$, o de mortes por atropelamento reduziu-se em $17 \%$.

\section{Novo sinal na faixa}

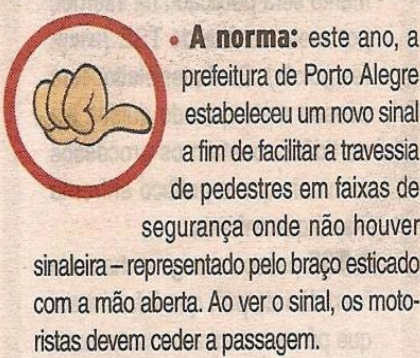

- Aplicação: pegou parciaimente. 0 número de mortes por atropelamento cail
17\% na Capital depois da adoção do novo sinal. O número total de atropelamentos, porém, passou de 811 para 881.

- Motivo: 0 diretor de trânsito da Empresa Pública de Transporte e Circulação, Vanderlei Capellari, afirma que o impacto da campanha pode ser medido pela redução significativa no número de mortes por atropelamento na Capital. Ainda que nem todos façam o sinal, a divulgação ajudou a elevar o respeito dos condutores pela faixa.

\section{Acidentes na Capital}

Confira variação na violência do trânsito porto-alegrense em períodos antes e depois do novo sinal:

\begin{tabular}{l|c|c|c} 
& Antes* & Depois** & Variação \\
Mortes por atropelamento & 52 & 43 & $-17 \%$ \\
Atropelamentos & 811 & 881 & $8 \%$ \\
Mortes em geral & 111 & 108 & $-3 \%$ \\
Acidentes & 15.316 & 15.853 & $3,5 \%$ \\
& & "Setembro de 2008 a abril de 2009 \\
& "Setembro de 2009 a abril de 2010
\end{tabular}

Figura 4: Avaliação do Programa "Novo Sinal" em reportagem da mídia

Fonte: Gonzatto (2010).

Resultados negativos não previstos são exemplificados neste caso, como no artigo de opinião "Novo sinal de trânsito: ilegal e perigoso"4, publicado pelo engenheiro Walter Kauffmann Neton em setembro de 2009, em vários blogs da Internet, e o acidente isolado em que, ao parar para uma mulher acompanhada de uma criança pequena que atravessava a faixa à sua frente, um motorista sofreu colisão traseira - ocasionado pelo terceiro carro na fila - e, em consequência do choque, atingiu a pedestre, que felizmente conseguiu jogar a tempo sua filha para a calçada, de modo que a criança saísse ilesa. $O$ acidente, apesar de fato isolado e ocorrido na primeira semana de lançamento do programa, teve grande repercussão na mídia, como páginas inteiras de jornais de circulação estadual (MELo, 2009). Além disso, houve discussão pública entre alunos e professores da OZI Escola de Audiovisual de Brasília, do

4 Disponível em: <http://ong-alerta.blogspot.com/2009_ 09_01_archive.html>. 


\section{Comunicação, inovação e avaliação no setor público: o uso de marketing social em dois diferentes casos no Rio Grande do Sul}

Distrito Federal e a agência Paim (de Porto Alegre), se o vídeo "Náufrago", integrante da campanha "Novo Sinal", não seria plágio do vídeo "llha", criado pelos alunos da instituição de ensino ${ }^{5}$.

Em reunião de avaliação geral com os entrevistados, algumas reflexões merecem destaque.

a) Acredita-se ser importante, na avaliação de um programa de marketing social, a variável "avaliação do momento político", antes de sua implementação. Argumentou-se que, no caso de órgãos públicos, há duas questões delicadas: o calendário eleitoral e a receptividade das pessoas. Pelo calendário do Tribunal Regional Eleitoral - TRE, nos 90 dias que precedem a eleição, as autoridades não podem mais investir em propaganda, salvo casos especiais analisados um a um pelo TRE. De qualquer forma, próximo às eleições, os cidadãos são refratários ao recebimento de material educativo por acharem que é material panfletário político-partidário, ou cuja motivação seja, ainda que veladamente, "eleitoreira". Observe-se aqui que, em avaliação interna da agência e da Prefeitura, um dos motivos da aceitação da campanha foi o insight, "corajosamente defendido pelo Prefeito", de assinar a campanha sem marca de governo, apenas com o brasão da Prefeitura, para descaracterizá-lo de campanha de governo, e revesti-lo com a imagem de uma campanha, de fato, "da cidade de Porto Alegre".

b) Julgou-se relevante que se proceda a uma análise de custos e recursos disponíveis, previamente a uma campanha, em função do processo de "engessamento" que o orçamento de um órgão público possa ter.

c) Verificou-se a sugestão, pela agência Paim, de que o pré-teste do material de comunicação de um programa de marketing social seja dividido em duas fases: um pré-teste interno e outro externo. Isso se deve ao fato de que, em uma estrutura pública como governo municipal ou estadual, a área de comunicação do órgão / secretaria terá de acordar o material à área técnica, bem como com as decisões de comunicação centralizadas pelo Comitê de Comunicação da Prefeitura (a exemplo do que ocorre no Estado). Assim, depois de a ideia ser "vendida" internamente, ela poderá ser testada junto ao público final, no pré-teste externo.

d) Houve a alegação, por parte de um dos participantes da Assessoria de Educação para o Trânsito, de que não necessariamente deve haver uma "mudança" a ser avaliada, mas que um programa pode ter êxito se, simples-

\footnotetext{
${ }^{5}$ Disponível em: <http://www.ozi.com.br/blog/?m=200909>, e em: $<$ http://www.propagandars.com.br/noticias_abrir. php?ct=1\&id=17>.
}

mente, "reforçou" o bom comportamento naquela audiência que já apresentava o comportamento desejado.

Um sentimento geral dos respondentes foi o de uma boa proposta de avaliação de uma campanha de educação para o trânsito não se baseia tão somente nos índices de mortalidade, uma vez que há várias causas que interferem nesses índices.

\subsection{Centro Estadual de Vigilância em Saúde/RS - Cevs/RS}

São vários os programas mantidos pelo Cevs/RS. Por esse motivo, a análise se restringe a dois deles, por sua relevância: o das hepatites virais e o da vacinação contra a gripe A - H1N1.

Especificamente para o caso das hepatites virais, como se trata de um programa recente, o Comitê Estadual Intersetorial de Enfrentamento das Hepatites Virais foi instituído em novembro de $2008^{6}$. Em fase de implementação, a avaliação somativa só ocorrerá ao final do governo atual, quando o comitê pretende entregar um plano consolidado ao novo governo, se não houver permanência da presente administração. Conforme estabeleceu o Decreto n. 45.996/ 2008, dentre as atribuições do Comitê está a de "[...] discutir e elaborar o Plano Estadual de Prevenção, Diagnóstico, Tratamento, Vigilância e Controle das Hepatites Virais, bem como acompanhar e avaliar a sua implementação [ênfase acrescentada]". Não obstante seu trabalho seja relativamente incipiente, indicadores estão sendo desde já levantados, como os preparados pela Secretaria de Educação - um dos órgãos integrantes, e mais atuantes, juntamente com a Secretaria da Saúde [a gerente do programa na Secretaria da Saúde, Dra. Miriam Vontobel, Cevs/ RS, estava em longa viagem ao exterior, durante a etapa de execução deste estudo de caso, o que levou à busca de outros cruzamentos de informações], que providencia relatório de quantas escolas foram visitadas e quantas palestras foram nelas proferidas ao público escolar.

Como estratégias de input, foi realizada uma oficina de planejamento estratégico pelo comitê, para dar início ao que se transformaria no Plano Estadual de Vigilância, Prevenção e Controle das Hepatites Virais. O plano foi desenvolvido até as medidas a serem tomadas, contudo a questão dos indicadores de avaliação ainda segue sendo discutida; ele vai sendo colocado em ação com base também na experiência empíricas dos participantes, "pois não se pode ficar esperando a coleta dos dados consolidados, seria irresponsabilidade, ou omissão". Conta-se, contudo, com

\footnotetext{
${ }^{6}$ RIo Grande do Sul. Gabinete da Governadora. Decreto n. 45.996. Institui o Comitê Estadual Intersetorial de Enfrentamento das Hepatites Virais. Porto Alegre, 17 de novembro de 2008.
} 


\section{Comunicação, inovação e avaliação no setor público: o uso de marketing social em dois diferentes casos no Rio Grande do Sul}

o embasamento científico multidisciplinar do comitê. É um plano que pretende ser mais de diretrizes do que propriamente de metas quantificadas, embora um dos objetivos seja expandir a prevenção e o tratamento dos atuais $25 \%$ para $70 \%$ das pessoas que fazem parte dos grupos de risco, com recursos já garantidos no orçamento.

Um dos problemas de determinação de metas quantificadas é o caráter intersetorial do programa. Se um determinado hospital municipal não desejar participar, ou seguir participando no combate às hepatites virais, não há instrumentos legais de imposição pelo Governo do Estado, o que leva então a um trabalho de convencimento, e nunca de coerção. A Secretaria de Educação de Canela, por exemplo, após reunião com o comitê, instituiu o "mês do combate às hepatites virais", com bons resultados de busca por exame e tratamento pelos moradores do município.

A avaliação é realizada, assim, em cunho formativo [de processo], pois, em cada reunião do Comitê, avaliam-se os passos dados por cada um dos integrantes desde a reunião anterior. Vai-se, da mesma forma, fazendo um mapeamento da rede pelos bancos de sangue e prefeituras.

Um dos esforços de processo direciona-se à produção de material impresso (Figura 5), de cunho informativo e educativo, tanto genérico sobre os vários tipos quanto segmentado demograficamente (a seguir, na Figura 6).

O Comitê Intersetorial avalia seu trabalho, em parte, pelo espaço que a mídia vem começando a dar ao problema, e

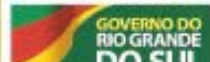 DOSUL \\ COAACEM PARA FAZE \\ BÊ-A-BÁ \\ Conheça um pouco mais sobre as Hepatites virais A, B e C. \\ Aprenda a prevenir. Proteja-se}

HEPATITES

Figura 5: Folder informativo geral sobre as hepatites virais Fonte: Comitê de Ação Solidária.

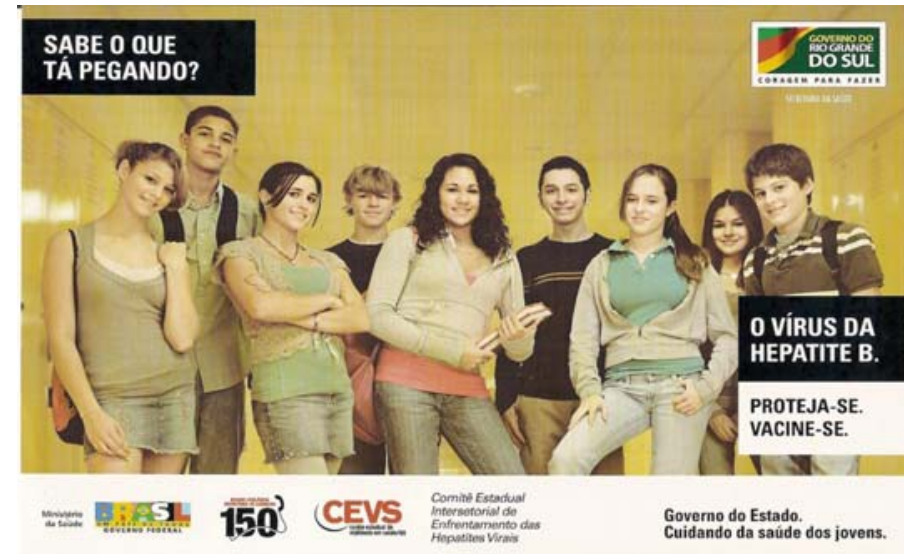

Figura 6: Volante informativo para jovens sobre as hepatites virais Fonte: Comitê de Ação Solidária.

essa variável é sobremaneira cara ao comitê, em função de que a informação à população é determinante para a prevenção, e por se tratar de uma questão complexa - as três formas de hepatites virais presentes no Estado requerem, cada uma, diferentes cuidados, como explanado em um programa de uma hora da TVE, e em duas páginas de uma reportagem do Caderno Vida do jornal Zero Hora, que funcionou "quase como uma cartilha". Por exemplo, quando a pessoa passa a saber que é uma portadora do vírus, "ela, no mínimo, deixa de ser uma transmissora" do mesmo.

Para Tarsila Crusius, a dificuldade dos indicadores parte da própria dificuldade da definição de metas, em razão do desafio gerado pela falta de dados sólidos, como é o caso das hepatites virais. Como é uma doença silenciosa, em que apenas se estima o número de portadores - na casa de $2 \%$ da população gaúcha já infectada - (não apenas no Rio Grande do Sul, mas em nível internacional), ter-se informações consolidadas, no sistema, já é uma das metas do mesmo. "Não há o 'marco zero' do problema, para que se possa ter um acompanhamento estatístico mais fidedigno", conforme esclareceu Tarsila, presidente do comitê. Por exemplo, no trânsito, o comportamento indesejado é relativamente ostensivo, observável. Mas os cuidados na não transmissão das hepatites virais, por comportamento íntimo (promiscuidade, falta de higienização na preparação dos alimentos, compartilhamento de aparelho de barba entre irmãos ou pais e filhos), são de difícil monitoramento. No entanto, o tema é preocupante para o governo e a sociedade, na medida em que a doença evitável - exige um tratamento crônico.

Há um grande dilema ético para o trabalho do comitê, que torna a questão uma "bomba-relógio" [sic]: "quanto menos informação, maior o problema, por haver mais casos de transmissão. Contudo, ao realizar o exame e saber que está infectado, pode ser inclusive pior por não haver, no 


\section{Comunicação, inovação e avaliação no setor público: o uso de marketing social em dois diferentes casos no Rio Grande do Sul}

sistema de saúde, estrutura logística e de recursos - a medicação é muito cara e de estocagem muito delicada para o grande atendimento a ser feito". No entanto, o compromisso ético foi o da divulgação dos riscos da doença: "Vai estourar no colo das prefeituras, e das secretarias de saúde, mas meu compromisso ético é o de minimizar esse impacto", afirmou a presidente do comitê.

A tarefa de segmentação de público no planejamento do programa é delicada na percepção da presidente do comitê: foram, sim, identificados grupos de risco, mais vulneráveis, tais como motoristas de caminhão, usuários de drogas injetáveis e manicures, dentre outros, "mas, na verdade, a população inteira, desde que não tenha sido vacinada, está vulnerável às diferentes formas do vírus". As hepatites virais são ainda mais preocupantes que a própria Aids, para a Sra. Tarsila, pois "o vírus da Aids sobrevive muito poucas horas ao ar livre, mas o vírus da hepatite pode resistir por até sete dias em uma gota de sangue", o que gera, por exemplo, o risco nas manicures, pelo uso de material cortante compartilhado entre as clientes sem a necessária esterilização.

Uma das formas de avaliação informal ocorre pelo retorno dado ao trabalho dos agentes de saúde, realizado de forma missionária pelo interior do Estado.

Como variável de processo, além das campanhas realizadas, há a disseminação dos Centros de Aplicação e Monitoramento de Medicamentos Injetáveis - Cammi, que, para efeitos de eficiência do sistema, otimizam a quantidade utilizada de interferon aos pacientes, a estocagem adequada do medicamento, bem como promovem um acompanhamento próximo do paciente, necessário devido às delicadas reações individuais à substância.

Tarsila reportou que algumas vezes o feedback vem de maneiras insólitas, como quando da visita que recebeu de um transexual, no comitê, como manifestação de apoio à ação do gabinete, em palestras realizadas, e de um senhor "muito simples", que assistiu a uma entrevista pela televisão, e a partir dela foi buscar ajuda no sistema de saúde, e identificou em si a doença, começando a tratá-la ainda a tempo de cura. Esse senhor, ao receber mais material informativo, na forma de DVDs, "custou a acreditar que estava ganhando algo, e se deixou levar pelas lágrimas". Tais situações pontuais, específicas, estão previstas na estrutura conceitual na categoria "resultados", variável "norma social", indicador "casos factuais", previsto para histórias incomuns ou curiosas.

Outra questão de saúde pública da qual se ocupa o Cesv/RS é a Campanha de Vacinação da Gripe A, com imunização contra o vírus $\mathrm{H} 1 \mathrm{~N} 1$. O saldo deste ano é positivo, na avaliação da Coordenação do Programa de Imunizações da Secretaria da Saúde. Conforme explicou a Dra. Maria Tereza
Schermann, "enquanto, em 2009, a gripe A matou pelo menos 292 pessoas na primeira onda da doença, não há um caso sequer registrado neste ano". Para a Dra. Tani Ranieri, o apoio intenso da mídia na divulgação das etapas de imunização foi primordial. O espaço em páginas de jornal e TV foi intenso, e praticamente todos os dias havia alguma entrevista a ser dada, por telefone, a rádios do Estado todo.

Como a campanha de vacinação é um "programa vertical", de abrangência nacional e orquestrada pelo Ministério da Saúde, a avaliação da mesma é feita por esse órgão federal. À Secretaria da Saúde, por meio do Cesv/RS, compete a operacionalização da campanha, embora haja um acompanhamento - de processo - que é feito diariamente, em tempo real, pelo qual o Cesv sabe o percentual de pessoas imunizadas em cada um dos grupos de risco e etapas de vacinação, por meio de uma ferramenta on-line ${ }^{7}$, alimentada por cada município no País, denominada "Vacinômetro", ilustrado na Figura 7 a seguir.

Pelo "Vacinômetro", de acompanhamento diário, verificase que $40 \%$ da população gaúcha foi imunizada, na campanha de 2010, finalizada no início do mês de junho. Esse monitoramento, que pode ser detalhado por município, é realizado diariamente pelo Cevs para verificar quais das seis etapas da campanha foram mais ou menos eficazes em termos de percentual da população de risco daquela etapa específica.

Não obstante ser um programa vertical, alguns materiais educativos são desenvolvidos pelo Cevs/RS, tais como cartazes, folhetos e propaganda em traseira de ônibus busdoor - com a temática da vacinação para a gripe A.

Em reunião com os principais envolvidos no programa, assomaram algumas considerações e reflexões acerca de

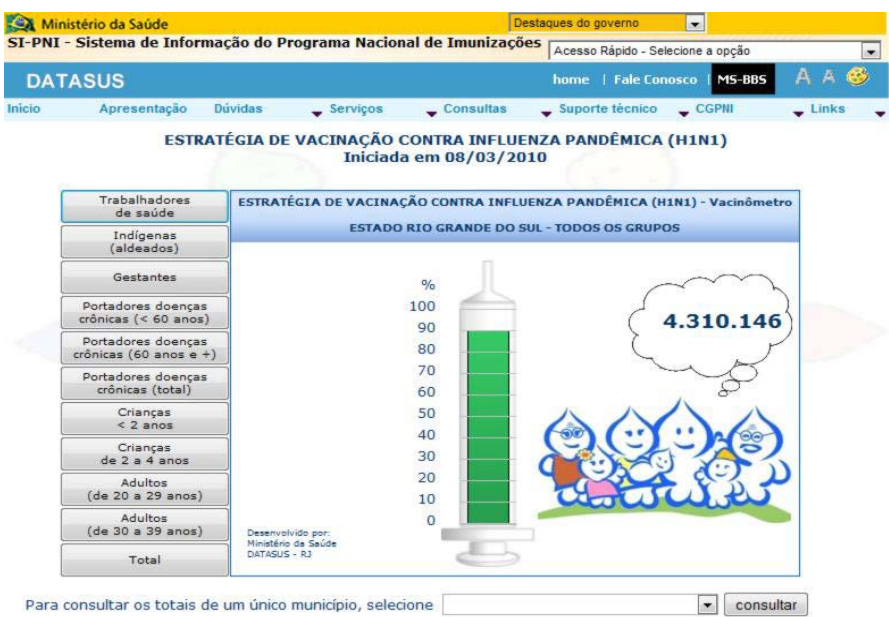

Figura 7: Acompanhamento on-line do total de pessoas imunizadas

${ }^{7}$ Disponível em: <http://pni.datasus.gov.br/consulta_h1n1_10>. 


\section{Comunicação, inovação e avaliação no setor público: o uso de marketing social em dois diferentes casos no Rio Grande do Sul}

programas de marketing social e sua avaliação, enumeradas na sequência.

a) Como material de subsídio de input de planejamento inicial, no caso específico do Cevs, um dos indicadores poderia ser a "situação epidemiológica".

b) Os participantes não se sentiram muito à vontade com alguns termos que Ihes parecem próprios da Administração ou do Marketing. Por exemplo, em vez de tratar o entendimento pelo público-alvo como "compreensão da campanha", preferem denominá-lo "lembrança da estratégia de vacinação" e, como formas de mensuração dessa variável, desdobrariam grupos focais em seis, cada um relativo ao público de cada etapa da vacinação contra a gripe $A$.

c) Registrou-se o entendimento de que é muito importante a avaliação da motivação dos próprios profissionais, além do público-alvo, pois "os agentes têm de acreditar na estratégia utilizada".

d) Como avaliação de comportamento concorrente ao comportamento desejado do público-alvo, ilustram com o exemplos dos hoaxes, ou boatos de Internet. Por vezes, uma contrainformação irresponsável é disseminada a um grande número de pessoas, afetando o sucesso de uma estratégia de controle epidemiológico.

e) As respondentes avaliaram que uma das consequências positivas não planejadas, quando da operação contra a gripe A, foi de que as pessoas voltaram aos "bons veIhos hábitos" de higienização das mãos, o que ajuda a controlar outras doenças que não somente a gripe $A$.

f) Considerou-se desnecessária uma avaliação ética dos resultados do programa, por entender-se que a avaliação ética deve ser feita no início, quando da fase de input, de planejamento do programa. Um dilema ético real ligado à vacinação da gripe $A$ foi o da segmentação de público (quatro a cada dez gaúchos foram vacinados). "Por que limitar a determinados segmentos, em vez de dar acesso universal?", questionou a coordenadora, e a resposta foi fornecida com base no informe técnico do Ministério da Saúde, que estabelecia a preferência pelos grupos mais acometidos, estatisticamente, pela gripe $A$, uma vez que não haveria insumo para imunizar todos, nem recursos humanos para tal operação. Outra questão ética delicada foi a de escolher imunizar, em primeiro lugar, os agentes de saúde (médicos, enfermeiros), em vez do restante da população. Os trabalhadores de clínicas e hospitais tiveram a preferência de inoculação da vacina. A escolha, nesse caso, também foi decidida por uma ética utilitarista: se não fossem vacinados primeiro, e contraíssem em larga escala a doença [como foi o caso em vários hospitais, em 2009], os trabalhadores da saúde poderiam, por sua ausência ou morte, "gerar o colapso em todo o sistema". Assim, cuidou-se antes dos "cuidadores" dos demais. Foi uma escolha ética de planejamento e de processo (de execução) do programa de marketing social.

\section{Discussão dos Resultados}

Uma análise comparativa, no Quadro 3, a seguir, entre os casos reporta o principal "produto vendido", os objetivos precípuos dos programas e a "concorrência" encontrada nas duas situações.

Ambas as instituições realizam sua avaliação dos resultados em três diferentes momentos, em um continuum cronológico, que parte de uma avaliação de diagnóstico, inicial, segue em uma avaliação de processo, que se convencionou chamar de formativa, e uma avaliação de resultados, ao final, normalmente designada como somativa, na literatura. Da mesma forma, os dois casos estudados esforçam-se por levar a seus públicos uma mudança comportamental que visa ao bem-estar individual e coletivo. Se Wiebe, no início da década de 1950, antecipava uma oportunidade "para o marketing vender mais do que sabonete", vender antes cidadania e qualidade de vida, no estágio atual de desenvolvimento de marketing social, viu-se que é possível, apenas é o momento de se aperfeiçoar as formas de fazê-lo.

Quadro 3: Diferenças simplificadas entre o marketing comercial e social

\begin{tabular}{|l|l|l|}
\hline & EPTC & Cesv RS \\
\hline Tipo de produto vendido & - Cidadania no trânsito & - Saúde da população \\
\hline Objetivo primário & $\begin{array}{l}\text { - Realização do "novo sinal" de trânsito } \\
\text { pelos pedestres, e respeito a ele pelos } \\
\text { condutores de veículos }\end{array}$ & $\begin{array}{l}\text { - Vacinação e cuidados profiláticos para com } \\
\text { os diferentes tipos de hepatites virais } \\
\text { Vacinação e cuidados profiláticos para com } \\
\text { a gripe A - H1N1 }\end{array}$ \\
\hline Concorrência(s) & $\begin{array}{l}\text { - Pressa dos motoristas } \\
\text { - Atenção deslocada para outros } \\
\text { elementos, inclusive dispositivos de } \\
\text { áudio e vídeo nos automóveis }\end{array}$ & $\begin{array}{l}\text { Crendices populares e temores sobre } \\
\text { vacinação } \\
\text { Boatos de Internet (hoaxes) }\end{array}$ \\
\hline
\end{tabular}

Fonte: elaborado pelos autores, a partir da estrutura de análise de Kotler, Roberto \& Lee (2002: 10). 


\section{Comunicação, inovação e avaliação no setor público: o uso de marketing social em dois diferentes casos no Rio Grande do Sul}

\section{Referências}

ANDREASEN, Alan. What is social marketing. Social Marketing Institute. Disponível em: <http://www.social-marketing.org>. Acesso em: 23 de fevereiro de 2008.

BARDIN, Laurence. Análise de conteúdo. Tradução de Luís Antero Reto e Augusto Pinheiro. Lisboa: Edições 70, 1977.

BARTELS, Robert. The identity crisis in marketing. Journal of Marketing, n. 38, p. 73-76, October, 1974.

BATES, Cynthia. Use of social marketing concepts to evaluate ocean sustainability campaigns. Social Marketing Quarterly, v. 16, n. 1, p. 71-96, March, 2010.

Boyd, Harper W.; Westfall, Ralph L. \& Stasch, Stanley F. Marketing research: text and cases. 7. ed. Homewood, IL: Richard D. Irwin, 1989.

Chance, Zoë \& DeshPandé, Rohit. Putting patients first: social marketing strategies for treating HIV in developing nations. Journal of Macromarketing, v. 29, n. 3, p. 220232, April, 2009.

Coelho, Simone de Castro Tavares. Terceiro Setor. um estudo comparado entre Brasil e Estados Unidos. São Paulo: Senac, 2000.

Cone, Carol; Phares, Lynn \& Gifford, Carol. Leveraging cause branding to effect social change: the convergence of cause branding and social marketing. Social Marketing Quarterly, v. VII, n. 3, Fall, 2001 [Special Session I].

Domegan, Christine T. The use of social marketing in evaluating science outreach programmes in Ireland. Irish Journal of Management, p. 103-125, January, 2007. Disponível em: <http://www.highbeam.com/doc/1P31429543091.html>. Acesso em: 8 de fevereiro de 2010.

Drumwright, Minette E. Company advertising with a social dimension: the role of noneconomic criteria. Journal of Marketing, v. 60, n. 4, p. 71-87, October, 1996.

FLICK, Uwe. Uma introdução à pesquisa qualitativa. 2. ed. Tradução de Sandra Netz; revisão técnica de Teniza da Silveira. Porto Alegre: Bookman, 2004.

FONTES, Miguel. Marketing social: novos paradigmas. Rio de Janeiro: Elsevier, 2008. 210p.

Fox, Karen F. A.\& KotLeR, Philip. The marketing of social causes: the first 10 years. Journal of Marketing, v. 44, p. 24-33, Fall, 1980.

GiacominI FiLho, Gino; Govatto, Ana Cláudia M.; Costa, Bárbara Regina L.; Silva, Édson C. \& KaHLER, Priscila Y. Responsabilidade social empresarial: parâmetros e atributos. In: UNIEMP INOVAÇÃo (org.). Inovação e responsabilidade social. 1. ed. São Paulo: Instituto Uniemp, 2004, v. 01, p. 11-28.
GIL, Antonio Carlos. Métodos e técnicas de pesquisa social. 5. ed. São Paulo: Atlas, 1999.

GonzatTo, Marcelo. Leis do trânsito: o que pegou e o que não pegou. Jornal Zero Hora, Porto Alegre, 13 de junho de 2010. Reportagem Especial, p. 4-5.

Gordon, Ross; McDermott, Laura; SteAd, Martine \& Angus, Kathryn. The effectiveness of social marketing interventions for health improvement: what's the evidence? Public Health, v. 120 , n. 12, p. 1.133-1.139, December, 2006.

Gordon, Ross \& Moodie, Crawford. Dead cert or long shot: the utility of social marketing in tackling problem gambling in the UK? International Journal of Nonprofit and Voluntary Sector Marketing, v. 14, n. 3, p. 243, London, August, 2009.

Hampson, Sarah E.; Martin, Julia; Jorgensen, Janel \& BARKER, Mary. A social marketing approach to improving the nutrition of low-income women and children: an initial focus group study. Public Health Nutrition, v. 12, v. 9, p. 1.563-1.569, Cambridge, September, 2009.

Kerin, Roger; Hartley, Steven; Berkowitz, Eric \& Rudelius, William. Marketing. 8. ed. São Paulo: McGraw-Hill, 2008.

Kotler, Philip \& Lee, Nancy. Marketing no setor público: um guia para um desempenho mais eficaz. Tradução de Gabriela Perizzollo e Patrícia Lessa Flores da Cunha. Porto Alegre: Bookman, 2008. 350p.

Kotler, Philip; Roberto, Ned \& Lee, Nancy. Social marketing: improving the quality of life. 2 . ed. Thousand Oaks, CA: Sage Publications, 2002.

Kotler, Philip \& Zaltman, Gerald. Social marketing: an approach to planned social change. Journal of Marketing, v. 35, p. 3-12, July, 1971.

Lefebvre, R. Craig \& Flora, June A. Social marketing and public health intervention. Health Education Quarterly, v. 15, n. 3, p. 299-315, Fall, 1988.

Machado, Sany Karla \& Damacena, Cláudio. Percepção dos consumidores acerca do marketing relacionado a causas: uma revisão da literatura. Base - Revista de Administração e Contabilidade da Unisinos, v. 3, n. 2, São Leopoldo, maio-agosto, 2006.

Melo, Itamar. Um acidente reforça o alerta. Jornal Zero Hora, RBS: Porto Alegre, 30 de setembro de 2009, p. 4 e 5.

Peattie, Ken \& Peattie, Sue. Social marketing: a pathway to consumption reduction? Journal of Business Research, v. 62, n. 2, p. 260-268, February, 2009.

Pringle, Hamish \& Thompson, Marjorie. Marketing social: marketing para causas sociais e a construção das marcas. Tradução de Maria Lúcia G. L. Rosa. São Paulo: Makron Books, 2000. 


\section{Comunicação, inovação e avaliação no setor público: o uso de marketing social em dois diferentes casos no Rio Grande do Sul}

RothschILD, Michael L. Reconsidering the underlying exchange in social marketing. In: RotHSCHILD, Michael \& ANDREASEN, Alan R. Special session summary: considering social marketing from the perspective of several consumer research paradigms. Advances in Consumer Research, v. 25, n. 1, p. 295-298, Provo, 1998.

SILVA, Edson Coutinho. A aplicação do marketing social ao planejamento, elaboração e implementação de políticas públicas de saúde. 2005. Dissertação (Mestrado) - Universidade Municipal de São Caetano do Sul. São Caetano do Sul: USCS.

SIRGY, M. Joseph; Morris, Michael \& SAmLI, Coskun. The question of value in social marketing: use of a quality of life theory to achieve long-term life satisfaction. American Journal of Economics and Sociology, v., 44, n. 2, p. 215228, April, 1985.

SMITH, Warren \& HIGGINS, Matthew. Cause-related marketing: ethics and the ecstatic. Business \& Society, v. 39, n. 3, p. 304-322, September, 2000 [Sage Publications, Inc.].
TENÓRIO, Fernando G. Um espectro ronda o Terceiro Setor: o espectro do mercado. Revista de Administração Pública, v. 33, n. 5, p. 85-102, Rio de Janeiro, setembro/outubro, 1999.

Vergara, Sylvia Constant. Métodos de pesquisa em Administração. 3. ed. São Paulo: Atlas, 2008.

Watson, Jennifer M.; Lomar, Scott L. Dodd, Virginia; Logan, Henrietta L. \& C $\mathrm{HOI}$, Youjin. Effectiveness of a social marketing media campaign to reduce oral cancer racial disparities. Journal of the National Medical Association, v. 101, n. 8, p. 774-783, Washington, August, 2009.

Wiebe, Gerhart D. Merchandising commodities and citizenship on television. Public Opinion Quarterly, v. 15, p. 679-691, Winter, 1951-1952.

Yin, Robert K. Estudo de caso: planejamento e métodos. Tradução de Daniel Grassi. 2. ed. Porto Alegre: Bookman, 2001. 